Document downloaded from:

http://hdl.handle.net/10251/105464

This paper must be cited as:

De Oña, J.; López-Maldonado, G.; Mujalli, R.; Calvo, FJ. (2013). Analysis of traffic accidents on rural highways using Latent Class Clustering. Accident Analysis \& Prevention. 51:1-10. doi:10.1016/j.aap.2012.10.016

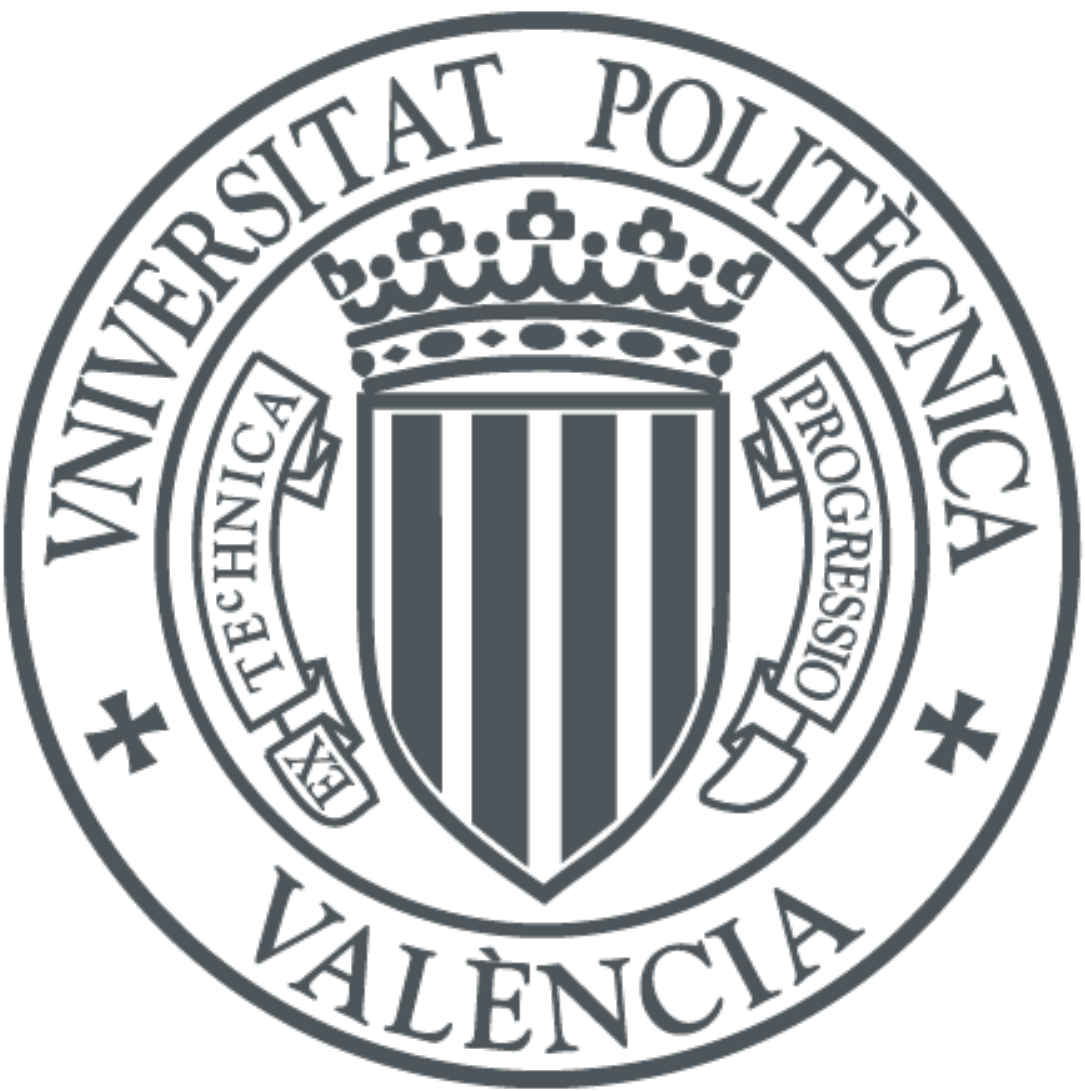

The final publication is available at

http://dx.doi.org/10.1016/j.aap.2012.10.016

Copyright Elsevier

Additional Information 
Analysis \& Prevention

Elsevier Editorial System(tm) for Accident

Manuscript Draft

Manuscript Number: AAP-D-12-00235R2

Title: Analysis of traffic accidents on rural highways using Latent Class clustering and Bayesian Networks

Article Type: Full Length Paper

Keywords: Cluster Analysis; Latent Class Clustering; Bayesian Networks; traffic accidents; classification; injury severity; highways; road safety

Corresponding Author: Dr. Juan de Oña, Ph.D.

Corresponding Author's Institution: University of Granada

First Author: Juan de Oña, Ph.D.

Order of Authors: Juan de Oña, Ph.D.; Griselda Lopez; Randa Mujalli, Ph.D.; Francisco Calvo, Ph.D.

Abstract: One of the principal objectives of traffic accident analyses is to identify key factors that affect the severity of an accident. However, with the presence of heterogeneity in the raw data used, the analysis of traffic accidents becomes difficult. In this paper, Latent class Cluster (LCC) is used as a preliminary tool for segmentation of 3,229 accidents on rural highways in Granada (Spain) between 2005 and 2008 . Next, Bayesian Networks (BN) are used to identify the main factors involved in accident severity for both, the entire database (EDB) and the clusters previously obtained by LCC. The results of these cluster-based analyses are compared with the results of a full-data analysis. The results show that the combined use of both techniques is very interesting as it reveals further information that would not have been obtained without prior segmentation of the data. BN inference is used to obtain the variables that best identify accidents with killed or seriously injured. Accident type and sight distance have been identify in all the cases analyzed; other variables such as time, occupant involved or age are identified in EDB and only in one cluster; whereas variables vehicles involved, number of injuries, atmospheric factors, pavement markings and pavement width are identified only in one cluster. 


\section{Analysis of traffic accidents on rural highways using Latent Class Clustering and Bayesian Networks}

Juan de Oña*, Griselda López, Randa Mujalli and Francisco J. Calvo

TRYSE Research Group. Department of Civil Engineering, University of Granada, ETSI Caminos, Canales y Puertos, c/ Severo Ochoa, s/n, 18071 Granada (Spain)

* Corresponding author. Phone: +34 9582499 79, jdona@ugr.es 


\title{
Analysis of traffic accidents on rural highways using Latent Class Clustering and Bayesian Networks
}

\begin{abstract}
One of the principal objectives of traffic accident analyses is to identify key factors that affect the severity of an accident. However, with the presence of heterogeneity in the raw data used, the analysis of traffic accidents becomes difficult. In this paper, Latent Class Cluster (LCC) is used as a preliminary tool for segmentation of 3,229 accidents on rural highways in Granada (Spain) between 2005 and 2008. Next, Bayesian Networks (BN) are used to identify the main factors involved in accident severity for both, the entire database (EDB) and the clusters previously obtained by LCC. The results of these cluster-based analyses are compared with the results of a full-data analysis. The results show that the combined use of both techniques is very interesting as it reveals further information that would not have been obtained without prior segmentation of the data. BN inference is used to obtain the variables that best identify accidents with killed or seriously injured. Accident type and sight distance have been identify in all the cases analyzed; other variables such as time, occupant involved or age are identified in EDB and only in one cluster; whereas variables vehicles involved, number of injuries, atmospheric factors, pavement markings and pavement width are identified only in one cluster.
\end{abstract}

Keywords: Cluster Analysis; Latent Class Clustering; Bayesian Networks; traffic accidents; classification; injury severity; highways; road safety

\section{INTRODUCTION}

Traffic accidents are contingent events and analysing them requires awareness of the particularities that define them. In general, accidents are defined by a series of variables generally discrete variables - that explain them. Once the nature of the variables is known, researchers select the method that is most appropriate for developing and implementing the best statistical models for analysing the data in each case (Lord and Mannering, 2010; Savolainen et al., 2011; Mujalli and de Oña, in press).

One of the main problems of accident data and their modelling process is their heterogeneity (Savolainen et al., 2011). If this is not taken into account during the analysis, certain relationships between the data may not be detected. Researchers often try to reduce heterogeneity by segmenting traffic accident data on the basis of expert domain knowledge, methodological decisions or the intention to study a specific problem. Although expert knowledge can lead to a workable segmentation, it does not guarantee that each segment consists of a homogenous group of traffic accidents (Depaire et al., 2008). That is why specific analysis techniques, such as cluster analysis (CA), are used as aids in traffic accident segmentation.

CA has been used in road safety analysis as a preliminary tool for attaining several aims. Karlaftis and Tarko (1998) used it to classify 92 areas of the state of Indiana into urban, suburban and rural areas. They applied Negative Binomial (NB) regression models to the results in order to analyse the influence of driver age on accidents. The results obtained with a model that used all the data and models based on clustered data showed statistically significant differences. Subsequently, Sohn (1999) used a Poisson regression model for previously clustered data (based on the latitude and longitude of each crash) to analyse accident frequency. Using CA, GIS (Geographic Information Systems) and NB models, Ng et al. (2002) developed an algorithm for estimating the number of accidents and evaluating their risk in a specific area. In a later study, Wong et al. (2004) proposed a method for evaluating the effect of a series of road safety 
strategies implemented in Hong Kong. They used CA as a preliminary step for grouping different road safety programmes and projects into smaller groups with significant road safety strategies. Ma and Kockelman (2006) used CA and a Probit model to analyse the relationship between crash frequency and severity, road design, and the characteristics of use in the state of Washington.

Depaire et al. (2008) used Latent Class Cluster (LCC) and Multinomial Logit (MNL) models to study the severity of traffic accidents. In their study, they identified seven clusters that represent different types of traffic accidents. Subsequently, they applied an MNL model to the full set of data and on each of seven identified clusters. Their results showed that the clustered data provided information that would not have been obtained if only the full database had been used. Recently, LCC have also been used by Park and Lord (2009) and Park et al. (2010) in order to segment a database and analyses vehicle crash data. Finally, Pardillo-Mayora et al. (2010) used CA to analyse data from run off road accidents to calibrate a roadside hazardous index for twolane roads in Spain. The four characteristics considered for the index were: roadside slope, nontraversable obstacles, safety barrier installation, and alignment. They used CA to group the 120 combinations of the four indicators into categories with homogeneous effects on severity.

Many previous studies have focused on compressing and identifying key factors that have an impact on the severity of the consequences of road accidents. Many different methodological approaches have been used to analyse severity (Savolainen et al., 2011): probit models (Bayesian ordered, binary, bivariate binary, bivariate ordered, heteroskedastic ordered, multivariate, ordered, random parameters ordered), logit models (bayesian hierarchical binomial, binary, generalized ordered, heteroskedastic ordered, markow switching multinomial, mixed generalized ordered, mixed joint binary, multinomial, nested, ordered, random parameters, random parameters ordered, sequential binary, sequential, simultaneous binary), log-linear model, partial proportional odds model, artificial neural networks, and classification and regression trees. Recently, Bayesian Networks $(\mathrm{BN})$ are being used to analyse traffic accident severity, with satisfactory results (Simoncic, 2004; De Oña et al., 2011; Mujalli and de Oña, 2011).

This paper presents an analysis of traffic accidents based on a combination of Cluster Analysis and Bayesian Networks. To the best of our knowledge, this is the first time that both approaches have been used together. The paper is structured as follows: Section 2 shows the methodology used to conduct the analysis, with a description of the Latent Class Clustering Analysis and Bayesian Network techniques. Next, key characteristics of the data analysed are described. Section 4 shows the results and discussion, followed by the conclusions.

\section{METHODOLOGY}

\subsection{Latent Class Clustering analysis}

CA is an unsupervised learning technique within the field of Data Mining, where its principal objective is to group a finite subset of elements in a number of groups or clusters. CA is based on heuristics that try to maximize the similarity between in-cluster elements and the dissimilarity between inter-cluster elements (Fraley and Raftery, 2002). The similarity-based techniques include two main approaches: the hierarchical approach (e.g. Ward's method, a single linkage method) and the partitioning approach (e.g. K-means). Both approaches have been used in road safety (Sohn, 1999; Karlaftis and Tarko, 1998; Ng et al., 2002; Wong et al., 2004; Pardillo-Mayora et al., 2010), although the statistical properties of these methods are relatively unknown (Fraley and Raftery, 2002).

Another type of CA is Latent Class Clustering (LCC) (Moustaki and Papageorgiou, 2005; Vermunt and Magidson, 2002). In this type, the statistical properties of probability model-based clustering techniques are better understood (Bock, 1996; Fraley and Raftery, 2002). Although 
when using any kind of cluster analysis method it is inevitable to introduce some kind of subjective judgment, LCC have some important advantages over other types of cluster analysis methods (Hair et. al, 1998, Madgison and Vermunt, 2002 and Vermunt and Magidson, 2005), such as:

- Being able to use different types of variables (frequencies, categorical, metric variables or a combination of them), with no need for prior standardization that could have a bearing on the results.

- The method provides several statistical criteria that help to decide the most appropriate number of clusters.

- LCC allow probability classifications to be made by using subsequent membership probabilities estimated with maximum likelihood method.

Given a data sample of $\mathrm{N}$ cases (or accidents), measured with a set of observed variables, $\mathrm{Y}_{1}, \ldots, \mathrm{Y}_{\mathrm{j}}$ which are considered indicators of a latent variable $\mathrm{X}$; and where these variables form a Latent Class Model (LCM) with T classes. If each observed value contains a specific number of categories: $\mathrm{Y}_{\mathrm{i}}$ contains $I_{i}$ categories, with $\mathrm{i}=1 \ldots \mathrm{j}$; then the manifest variables make a multiple contingency table with $\prod_{i=1}^{j} I_{i}$ response patterns. If $\pi$ denotes probability, $\pi\left(X_{t}\right)$ represents the probability that a randomly selected case belongs to the latent $t$ class, with $t=1,2, \ldots, T$.

The regular expression of LCMs is given by:

$$
\pi_{Y_{i}}=\sum_{t=1}^{T} \pi_{X_{t}} \pi_{Y_{i} \mid X_{t}}
$$

With $Y_{i}$ response-pattern vector of case $\mathrm{i} ; \pi\left(X_{t}\right)$ is the prior probability of membership in cluster $\mathrm{t} ; \pi_{Y_{i} \mid X_{t}}$ is the conditional probability that a randomly selected case has a response pattern $Y_{i}=$ $\left(\mathrm{y}_{1, \ldots, \mathrm{y}_{\mathrm{j}}}\right)$, given its membership in the $\mathrm{t}$ class of latent variable $\mathrm{X}$. Local independence is the underlying assumption that needs to be verified, and therefore Eq. (1) is re-written:

$$
\pi_{Y_{\mathrm{i}}}=\sum_{t=1}^{T} \pi_{X_{\mathrm{t}}} \Pi_{i=1}^{j} \pi_{\left.Y_{\mathrm{i} j}\right] \mathrm{X}(\mathrm{t})} \quad \text { with } \sum_{\mathrm{i}=1}^{\mathrm{j}} \pi_{\left.\mathrm{Y}_{\mathrm{i}}\right] \mathrm{X}(\mathrm{t})}=1 \text { and } \sum_{\mathrm{t}=1}^{\mathrm{T}} \pi_{\mathrm{X}_{\mathrm{t}}}=1
$$

For a detailed explanation of LCC analysis see Sepúlveda (2004).

The estimation of the model is based on the nature of the manifest variables, since it is assumed that the conditional probabilities may follow different formal functions (Vermunt and Magidson, 2005). The method of maximum likelihood is the most widely used method for estimating the model's parameters. Once the model has been estimated, the cases are classified into different classes by using the Bayes rule to calculate the a posteriori probability that each $\mathrm{n}$ subject comes from the $t$ class (^ are the model's estimated values):

$$
\pi_{\mathrm{X}_{\mathrm{t}}\left[\mathrm{Y}_{\mathrm{i}}\right.}=\frac{\left.\bar{\pi}_{\mathrm{X}_{\mathrm{t}}}^{-} \mathrm{T}_{\mathrm{Y}}\right] \mathrm{X}_{\mathrm{t}}}{\widehat{\pi}_{\mathrm{Y}_{\mathrm{i}}}}
$$

In practice, the set of probabilities is calculated for each response pattern and the case is assigned to the latent case in which the probability is the highest. Thus, a specific accident may belong to different latent cases with a specific percentage of membership (with $100 \%$ being the sum total of membership probabilities).

\subsection{Number of clusters selection}

Given that the number of clusters is unknown at the start, the aim is to find the model that can explain or adapt the best to the data being used. In this paper we have used several information criterions for discovering the model that provides the most information on reality. The criterions are: Bayesian Information Criterion (BIC) (Raftery, 1986), Akaike Information Criterion (AIC) 
(Akaike, 1987) and Consistent Akaike Information Criterion (CAIC) (Fraley and Raftery, 1998).

In clustering contexts, the BIC criterion has shown better performance than other criteria (Biernacki and Govaert, 1999). In general, the lower the value of the indicators, the better the model is, because it is more parsimonious and adapts better to the data. Nonetheless, when analysing large samples, the BIC and other information criteria often do not reach a minimum value with increasing number of clusters (Bijmolt et al., 2004). In that case, the percentage of reduction in BIC between competing models must be analysed, and additional criteria, such as entropy, should be used to select the optimal number of clusters. Entropy (Eq. 5) varies between 0 and 1 , and values over 0.90 denote a clear cluster differentiation; and also the interpretability of the clusters (McLachlan and Peel, 2000).

$$
\mathrm{I}(\mathrm{t})=1-\frac{\sum_{\mathrm{i}=1}^{\mathrm{N}} \sum_{\mathrm{t}=1}^{\mathrm{T}} \pi_{\mathrm{X}} \mathrm{X}_{\mathrm{i}} \ln \left(\pi \mathrm{X}_{\mathrm{t}} \mathrm{Y}_{\mathrm{i}}\right)}{\operatorname{Nln}(1 / \mathrm{T})}
$$

\subsection{Bayesian Networks}

Bayesian Networks' (BN) applications have grown extensively into different fields, with theoretical and computational developments in many areas (Mittal et al., 2007), including: modelling knowledge in bioinformatics, medicine, document classification, information retrieval, image processing, data fusion, decision support systems, engineering, gaming, and law.

Let $U=\left\{x_{1}, \ldots, x_{n}\right\}, n \geq 1$ be a set of variables. A BN over a set of variables $U$ is a network structure, which is a Directed Acyclic Graph over $U$ and a set of probability tables $B_{p}=$ $\left\{p\left(x_{i} \mid p a\left(x_{i}\right), x_{i} \in U\right)\right\}$ where $p a\left(x_{i}\right)$ is the set of parents or antecedents of $x_{i}$ in $\mathrm{BN}$ and $i=(1,2,3, \ldots, n)$. A BN represents joint probability distributions $P(U)=\prod_{x_{i} \in U} p\left(x_{i} \mid p a\left(x_{i}\right)\right)$.

Relationships between variables based on the theory of BN (Neapolitan, 2004), represented by arcs in the graph, could represent causality, relevance or relations of direct dependence between variables. However, for the purpose of this research we do not assume a causal interpretation of the arcs in the networks such as in Acid et al. (2004). Consequently, the arcs are interpreted as direct dependence relationships between the linked variables, and the absence of arcs means the absence of direct dependence between variables; however, indirect dependence relationships between variables could exist.

The classification task consists in classifying a variable $y=x_{0}$, called the class variable, given a set of variables $U=x_{1} \ldots x_{n}$, called attribute variables. A classifier $h: U \rightarrow y$ is a function that maps an instance of $U$ to a value of $y$. The classifier is learned from a dataset $\mathrm{D}$ consisting of samples over $(U, y)$. The learning task consists of finding an appropriate $\mathrm{BN}$ given a data set $\mathrm{D}$ over $U$.

Following previous research (De Oña et al., 2011 and Mujalli and De Oña, 2011), the hillclimbing search algorithm and the MDL score were used to build the BNs for each one of the clusters selected in the previous step. The search algorithm and the score were applied in this study mainly because, besides being widely used and quick, they produce good results in terms of network complexity and accuracy (Madden, 2009).

\subsection{Performance evaluation indicators}

Several indicators were used to measure the model fitting for each one of the clusters. The indicators used in this study were accuracy, specificity, sensitivity, the harmonic mean of sensitivity and specificity (HMSS), and the ROC area. 


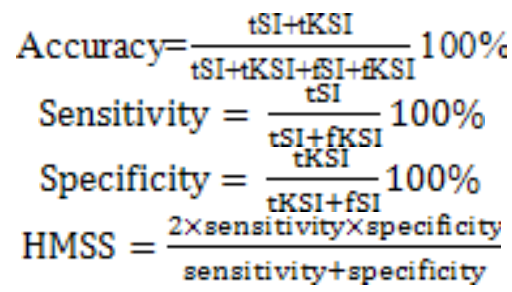

Where $t S I$ is true slight injured cases, $t K S I$ true killed or seriously injured cases, $f S I$ false slight injured cases, and $f K S I$ false killed or seriously injured cases.

Accuracy (Eq. 6) is a proportion of instances that were correctly classified. Accuracy only gives information on the classifier's overall performance. Sensitivity (Eq. 7) represents the proportion of correctly predicted SI among all the observed SI. Specificity (Eq. 8) represents the proportion of correctly predicted KSI among all the observed KSI. Another measure was the Harmonic Mean of Sensitivity and Specificity (HMSS), which gives an equal weight both of sensitivity and specificity (Eq. 9).

However, a trade-off exists between sensitivity and specificity. Therefore, we used the area under a Receiver Operating Characteristic (ROC) curve as a target performance measure. ROC curve represents the true positive rate (sensitivity) vs. the false positive rate (1-specificity). ROC curves are more useful as descriptors of overall performance, reflected by the area under the curve, with a maximum of 1.00 describing a perfect test and an ROC area of 0.50 describing a valueless test.

\subsection{BN inference}

Inference in BNs consists of computing the conditional probability of some variables, given that other variables are set to evidence. Inference may be done for a specific state or value of a variable, given evidence on the state of other variable(s). Thus, using the conditional probability table for the BN built, their values can be easily inferred. See De Oña et a. (2011) for a detailed explanation and examples.

When using BNs, inference is necessary to interpret the analysis results from the road safety perspective.

\section{DATA}

Accident data were obtained from Spanish General Traffic Accident Directorate (DGT) for rural highways for the province of Granada (South of Spain) for a period of 5 years (2004-2008). Only data for 1,2 or 3 involved vehicles were used for this analysis. The total number of accident's records used is 3,229 . Table 1 provides information on the data used for this study.

\section{(Table 1)}

Considering that the main objective of this study is to identify the key factors that affect the severity of traffic accidents, 18 explanatory variables based on De Oña et al. (2011) were used, and injury severity was considered a class variable, with two classes: slightly injured (SI), or killed or severely injured (KSI).

The data included variables describing the conditions that contributed to the accident and injury severity: characteristics of the accident (month, time, day type, number of injuries, number of occupants, accident type, number of involved vehicles and cause); weather information (prevailing weather conditions and lighting); driver characteristics (age and gender); and road characteristics (pavement width, lane width, shoulder width, paved shoulder, pavement markings and sight distance). 


\section{RESULTS AND DISCUSSION}

\subsection{Cluster analysis}

Latent GOLD software (v.4.0) was used for LCC analysis. Table 1 shows the 18 variables used, with injury severity as a dependent variable. In order to select the number of clusters, 10 models were generated (from one to 10 clusters). Figure 1 shows the evolution of BIC, AIC and CAIC for the 10 models. Increasing the number of clusters reduces BIC, AIC and CAIC values, but a higher degree of clusters implies a higher degree of complexity, leading to a less obvious clustering structure, despite a better statistical fit.

From a practical point of view, it is no so useful to have a marginal improvement in statistical fit, but a higher degree of complexity. So, as a tradeoff between statistical fit and complexity of clustering structure the model selected is the one with 4 clusters. In any case, this selection is in accordance with the literature: Depaire et al. (2008) selected the model where BIC and CAIC hardly show any additional improvement; Scheire et al. (2008) chose a model in which the differences attained are less than 1\%; In addition, the entropy for model 4 is 0.9873 , which indicates a good separation between clusters (McLachlan and Peel, 2000).

\section{(Figure 1)}

Having ascertained the number of clusters, the next step consisted in characterizing them. To that end, it was necessary to identify the most important categories within each cluster for each variable (using for that the highest conditional probability obtained for a determined category of a variable given its membership to a specific cluster).

Therefore, the characterization was based on utilizing the variables that permitted differentiation between clusters. Having performed the analysis, it was found that not all the variables could be used for the established target for the following reasons:

- The highest value of probability was obtained for the same category of a specific variable in all of the clusters built. This occurs in the variables time (TIM), number of injuries (NOI), cause (CAU), atmospheric factors (ATF), lighting (LIG), age (AGE), pavement markings (ROM) and sight distance (SID). For example, in the case of the variable TIM, the highest probability of having an accident at each of the 4 target clusters of the study is obtained in the same time period (12-18]. It should be noticed that although this variable does not permit a characterisation of the clusters, it permits knowing that the highest probability of accidents occurs during this time period.

- The probability values are distributed homogeneously between every possible category of a variable; and therefore it does not permit clusters' characterization. This occurs in the variables month (MON) and day (DAY) (i.e. in cluster 1, the probability for each category of MON (Winter, Spring, Summer and Autumn) are 24.82\%, 23.15\%, 26.48\% and $25.55 \%$, respectively, and the same is true in clusters 2,3 and 4 . Thus, with these results, it is not possible to say that an accident would have a higher probability of occurrence in a specific season).

Finally, Table 2 shows the five variables selected to characterise the clusters, along with their probability in each one of the 4 clusters identified.

\section{(Table 2)}

CLUSTER 1 (C1). It includes $100 \%$ of the accidents with 2 occupants or more, which occur on highways with a shoulder that is less than $1.5 \mathrm{~m}$ in $77 \%$ of the cases and is a paved shoulder in almost $100 \%$ of the cases. The collisions (with $94 \%$ of probability) are the type of accident that characterize $\mathrm{C} 1$, highlighting angle or side collisions (54\%); in $88 \%$ of the cases 2 vehicles were 
involved in the accident. Thus, based on these characteristics, $\mathrm{C} 1$ could be called: "Collisions on highways with shoulder".

CLUSTER 2 (C2). It includes $67 \%$ of the accidents in which only one occupant was involved, and which occur on highways with a shoulder width of $1.5 \mathrm{~m}$ in $78 \%$ of the cases, and that have a $99 \%$ probability of being paved. They are accidents that are caused by run-off-road with/without collision (83\%), in which one vehicle was involved with $99 \%$ of probability. C2 could be called: "Run-off-road accidents and collisions with pedestrians on highways with shoulder".

CLUSTER 3 (C3). It includes any accident with 2 occupants or more $(0 \%$ of probability for 1 occupant); but with a deviance in cluster 1, these are produced on highways without a shoulder or with an impractical shoulder (99\%). The types of accident that characterize this cluster are collisions (with $94 \%$ of probability). Based on these characteristics, it is observed that $\mathrm{C} 1$ and C3 overlap. C3 could be called: "Collisions on highways with no shoulders".

CLUSTER 4 (C4). This cluster contains $61 \%$ of the accidents with 1 occupant. They occur on highways that have no shoulder (99\%). The type of accident that characterizes them is the runoff-road with/without collision (85\%), and in $100 \%$ of the cases there is only one vehicle involved. Once again it is observed that $\mathrm{C} 2$ and $\mathrm{C} 4$ overlap. C4 could be called: "Run-off-road accidents and collisions with pedestrians on highways with no shoulders".

The previous definitions and values in Table 2 show that the data in $\mathrm{C} 1$ and $\mathrm{C} 3$ are more homogeneous that the data in $\mathrm{C} 2$ and $\mathrm{C} 4$. Table 3 shows the number of cases in each cluster that ranges between $19 \%$ and $40 \%$ of the total sample size. C1 stands out with close to 1,300 cases, whereas C2, C3 and C4 are similar in size, with 600-700 cases.

(table 3)

With the data used in this study, four different clusters were identified, based on accident type, the number of vehicles and occupant involved, the shoulder type and the shoulder pavement. It should be highlight that the descriptive cluster analysis in this paper is focused on getting a concise description for each cluster, which will be useful during the interpretation of BN results.

\subsection{Severity injury analysis}

Bayesian Networks (BN) are used in order to identify the main factor that contribute to crash severity. $\mathrm{BN}$ were built for the entire database (EDB) and for each one of the four clusters $(\mathrm{C} 1$, C2, C3 and C4) identified with LCC. The objective is to verify if new information and insights are obtained from the conjoint analysis (LCC and BN). First, the five BNs were compared in terms of performance indicators and complexity in order to evaluate the goodness of the models obtained. Next, the possibility of obtaining new information and insights from the clusters was studied in terms of direct dependent relationships between the variables for each BN and an analysis of the inference in the BNs for the clusters that improve the performance indicators, compared to the EDB.

\section{(Table 4)}

Table 4 shows accuracy, sensitivity, specificity, ROC area and HMSS for the EDB and clusters $\mathrm{C} 1$ to $\mathrm{C} 4$. ANOVA test was performed to measure the statistical significant difference for each cluster as compared to the EDB $(\mathrm{p}<0.05)$. The values of accuracy range from $64.0 \%$ in $\mathrm{C} 1$ to $55.1 \%$ in $\mathrm{C} 4$. These values are within the same range found in previous studies (Abdelwahab and Abdel-Aty, 2001; De Oña et al., 2011; Mujalli and De Oña, 2011) that used classification techniques for similar objectives. Table 4 shows that only $\mathrm{C} 1(64.0 \%)$ achieved a statistically significant improvement of accuracy as compared with results obtained for the EDB (59.5\%). 
C3 obtained similar accuracy results to these obtained in the EDB (58.9\% versus 59.5\%). The minimum accuracy is obtained in $\mathrm{C} 4$, which is also the smallest cluster. With regard to sensitivity, both $\mathrm{C} 1$ and $\mathrm{C} 3$ obtained significant improvements if compared to the EDB. The same repeats for specificity and for HMSS. For ROC area, only $\mathrm{C} 1$ improves significantly $(67.0 \%)$ with respect to $63.0 \%$ obtained for the EDB.

Another factor to be taken into consideration is network complexity (number of arcs). All the clusters' networks show a fewer number of arcs than the EDB (33 arcs): C2's BN is the simplest with 19 arcs; C1, C3 and C4 present 21 arcs.

On the basis of these results, LCC enabled the identification of two clusters ( $\mathrm{C} 1$ and $\mathrm{C} 3$ ) where the BN models' overall performance improved with regards to the EDB. This was not the case for clusters $\mathrm{C} 2$ and $\mathrm{C} 4$, where the results were not as good as they were for $\mathrm{C} 1$ and $\mathrm{C} 3$, and they did not improve the results obtained for the EDB's BN model.

Subsequently, on the basis of the BNs built for the EDB and the 4 clusters, it was possible to identify the direct dependence relationships between severity (SEV) and the dependant variables considered in the analysis. Table 5 shows the direct relationships between variables that were present either in the clusters or in the EDB. The clusters that share the same relationships are listed under the same group; in which the group refers to the number of BN that share the same relation (e.g. the relationship "time $\rightarrow$ lighting" (TIM $\rightarrow$ LIG) exists in the BNs built using all the 4 clusters as well as using the EDB, however, the relationship "severity $\rightarrow$ atmospheric factors" $(\mathrm{SEV} \rightarrow \mathrm{ATF})$ exists only in the 4 clusters).

\section{(Table 5)}

Table 5 shows that no direct relationship of dependency between severity (SEV) and lane with (LAW) can be observed in any of the cases (neither the EDB nor the clusters). As indicated in Section 2.2, this does not mean that no relationship between SEV and LAW exists; only that the relationship is not direct. In this case, indirect dependence relationships exist through other variables, such as pavement width (PAW) and pavement markings (ROM) in the EDB, C3 and $\mathrm{C} 4$, or PAW in $\mathrm{C} 1$ and $\mathrm{C} 2$ (see Table 5).

Several variables, such as month (MON), time (TIM), day (DAY), number of injuries (NOI), accident type (ACT), cause (CAU), age (AGE), gender (GEN), pavement width (PAW), shoulder type (SHT), pavement markings (ROM) and sight distance (SID), present a direct dependence relationship with severity (SEV) in all groups. The fact that they appear in all the groups may indicate that these variables have a strong correlation with SEV. There are also other three direct relations that appear in all groups: time $\rightarrow$ lighting (TIM $\rightarrow$ LIG); number of injuries $\rightarrow$ occupants involved (NOI $\rightarrow \mathrm{OI}$ ); and pavement width $\rightarrow$ lane width (PAW $\rightarrow \mathrm{LAW}$ ). All the results are coherent because the variables are highly correlated with each other.

However, the main reason for using LCC analysis prior to BNs is to identify relationships that only occur in specific clusters and not in the EDB or in the other clusters. Table 5 shows relationships identified in the clusters that are not identified when only the EDB is analysed. The table shows that a direct dependence relationship between severity and number of vehicles involved in the accident $(\mathrm{SEV} \rightarrow \mathrm{VI})$ only exists in $\mathrm{C} 2$. Table 5 also shows a direct relationship between severity and occupant involved (SEV $\rightarrow \mathrm{OI})$ only for EDB and $\mathrm{C} 3$. There are two direct dependence relationships that appear in three groups: severity with paved shoulder $(\mathrm{SEV} \rightarrow \mathrm{PAS}$ ) is observed in $\mathrm{C} 1, \mathrm{C} 2$ and $\mathrm{C} 4$; and severity with lighting ( $\mathrm{SEV} \rightarrow \mathrm{LIG}$ ) is observed in the $\mathrm{EDB}, \mathrm{C} 2$ and $\mathrm{C} 4$. The direct relationship between severity and atmospheric factors $(\mathrm{SEV} \rightarrow \mathrm{ATF})$ is present in all the four clusters but not in the EDB.

It is also worth mentioning a series of direct dependence relationships between SEV and other variables that have been identified in the clusters' BN but not in the EDB's BN. These are: 
A direct link between SEV and atmospheric factors (ATF) is present in all the four clusters' BNs but it is not present for the EDB. In this case, an indirect dependence relationship exists through month (MON).

- A direct link between SEV and paved shoulder (PAS) is present in BNs of clusters C1, C2 and $\mathrm{C} 4$ but it is not present for the EDB. In this case, an indirect dependence relationship exists through several variables: pavement width (PAW), pavement markings (ROM), sight distance (SID) and shoulder type (SHT).

- A direct link between SEV and vehicles involved (VI) is present in C2's BN but it is not present for the EDB. In this case, an indirect dependence relationship exists through several variables: accident type (ACT), age (AGE), gender (GEN), time (TIM), number of injuries (NOI) and occupants involved (OI).

The preceding analysis allowed the identification of further relationships between variables for certain types of accidents (clusters), which would not have been obtained without prior segmentation of the data. However, we focus on $\mathrm{BN}$ inference to analyse the results from a road safety perspective. Inference is used to determine the most significant variables that are associated with KSI (killed or severely injured) accidents for the EDB, $\mathrm{C1}$ and $\mathrm{C} 3$. The analysis was not made for the $\mathrm{BN}$ models for $\mathrm{C} 2$ and $\mathrm{C} 4$ because their performance indicators were poorer than the EDB's BN model.

\section{(Table 6)}

Table 6 assists in the identification of variables and values that contribute the most to the occurrence of a KSI individual in a traffic accident considering each one of the three BN models (EDB, $\mathrm{C} 1$ and $\mathrm{C} 3$ ). Since it is intended to determine which values of variables contribute the most to the occurrence of a KSI individual in a traffic accident, this table does not include the variables and values in which the values of probabilities of SI are always higher than those of $\mathrm{KSI}$ in the EDB, $\mathrm{C} 1$ and $\mathrm{C} 3$.

For each variable and each BN model, the probability of a value was set to be 1.0 (setting evidence) and the other values of the same variable were set to be 0.0. Thus, the associated probability of severity was calculated. Underlined values in Table 6 show the values of variables in which the probability of a KSI was found to be higher than that of SI.

For the EDB, Table 6 shows that assigning a probability of 1.0 to the value $\mathrm{CP}$ (collision with pedestrian) of the variable accident type (ACT), the probability of SI becomes 0.3316 and the probability of KSI becomes 0.6683 . These probabilities are calculated from the conditional probability table of the BN built for the EDB.

Setting evidences for the values of variables used to build the BN indicated that accident type (ACT), sight distance (SID), time (TIM), occupant involved (OI), age (AGE), and lighting (LIG) were found to be significant for the EDB. This results are coherent with previous studies which have highlighted some of this variables as key variables in KSI accidents (Abel-Aty 2003; Al-Ghamdi, 2002; de Oña et al., 2011; Gray et al., 2008; Helai et al., 2008; Kashani and Mohyamany, 2011; Kockelman and Kweon, 2002; Pande and Abel-Aty, 2009; Montella et al., 2011).

Setting evidences in the cluster's BN models (C1 and $\mathrm{C} 3)$ shows similarities and differences with the EDB results (see Table 6). The main similarities are:

Although the values change with regards to the EDB, the variables accident type (ACT) and sight distance (SID) are also significant in the case of $\mathrm{C} 1$ and $\mathrm{C} 3$.

EDB and C3 show very similar results when setting evidences for the values of time (TIM), occupant involved (OI) and age (AGE). 
Accident type (ACT) has been identified in several previous studies (Al-Ghamdi, 2002; de Oña et al., 2011; Kashani and Mohyamany, 2011; Montella et al., in press) as one of the key variables in accident severity. Particularly, in this study head-on collision (HOC) and collision with pedestrian $(\mathrm{CP})$ were the type of accident with the highest probability of KSI (see Table 6). These results agree with Kockelman and Kweon (2002), who found that head on crashes were more dangerous than angle crashes, left-side, and right-side crashes; moreover, they found that they were significant in accidents that involved KSI. Chang and Wang (2006) demonstrated that collisions with pedestrian had a higher risk of injury than other types of collision. And de Oña et al., (2011) highlighted that head on collision and rollover were more significant in KSI accidents.

Yan et al. (2008) found that drivers suffering from poor visibility are less likely to attempt to avoid crashes. And Montella (2011) identified that an inadequate sight distance was a major factor contributory in roundabout crashes. This study shows that if sight distance (SID) is restricted by the topography (TOP) or buildings (BUI) the probability of KSI accident increases.

The number of occupants involved (NOI) in a traffic accident was found to be a significant variable by Dupont et al. (2010). They found that the higher the number of vehicles involved in an accident and the level of occupancy of these vehicles, the higher the probability for each car occupant to survive. This agrees with our results in which the probability of KSI accident increases if there is only one occupant involved.

In accordance with previous studies (Tavris et al., 2001; Mujalli and de Oña, 2011), our results show that teenagers (TEE) have a higher probability of KSI accidents. Tavris et al. (2001) found that young people between 16 and 24 years were much more likely to be involved in KSI accidents than older drivers.

When lighting conditions (LIG) are without lighting (WL) the probability of KSI is higher. This result was also found by Gray et al. (2008). They identified that more severe injuries are predicted during darkness. Abel-Aty (2003) and Helai et al. (2008) found the same results. Pande and Abel-Aty (2009) concluded that there is a significant correlation between lack of illumination and high severity crashes. Finally, de Oña et al. (2010) also pointed out that KSI accidents are associated with roadways without lighting. This study shows that accidents between 0 and 6 hours have a significant probability of being KSI. Our results also show that the variables time (TIM) and lighting conditions (LIG) are directly correlated (see Table 5).

The main differences found between the clusters and the EDB's inference are the following (see Table 6):

- The lighting variable (LIG) is not identified as significant in clusters $\mathrm{C} 1$ and C3.

- The variables time (TIM), occupants involved (OI) and age (AGE) are not identified as significant in cluster $\mathrm{C} 1$, which refers to collision on highways with shoulders.

- The variable vehicles involved (VI), when only 1 vehicle is involved, is identified as significant in KSI accidents in cluster C3. This cluster contains very few accidents with only one vehicle involved; however all of them present KSI consequences.

- The variables number of injuries (NOI), atmospheric factors (ATF), pavement markings $(\mathrm{ROM})$ and pavement width (PAW) are only identified as significant in cluster $\mathrm{C} 1$.

\section{CONCLUSIONS AND RECOMENDATIONS}

This paper presents an analysis of traffic accident injury severity on rural highways conducted with the combined use of LCC and BN. The study uses 3,229 traffic accidents' records on rural highways. It is based on the standard police reports used in Spain, with information about 18 variables related with the injury severity of the accidents. 
LCC analysis identified four clusters ( $\mathrm{C} 1$ to $\mathrm{C} 4)$ based on the variables accident type, shoulder type, paved shoulder, occupant involved and number of vehicle involved. The main differences in cluster identification are accident type (collisions or run-off road), and the existence of paved shoulders on highways. Therefore, the conclusion is that the two variables are important in accident analyses.

BNs were built for each one of the four clusters and for the entire database (EDB). Accuracy, sensitivity, specificity, ROC area and HMSS were used as indicators for comparing model fitting (EDB's BN vs. the clusters' BN). The models of clusters C1 and C3 (which showed the highest homogeneity) show global results that are identical to or better than the model using the EDB. Therefore, the results show that increasing homogeneity improves the models' overall fitting.

The results were compared with the $\mathrm{BN}$ that uses the EDB and the BNs generated for each cluster in terms of: direct dependence relationships between severity (SEV) and all the others variables for EDB and for all the clusters; and inference for EDB and for the two clusters that improved the performance indicators with regards to the EDB ( $\mathrm{C} 1$ and $\mathrm{C} 3)$. This comparison has provided information and insights from the analysis that would not have been obtained if only the EDB had been analysed, without making a LCC analysis beforehand.

For instance, it can be seen that a set of variables (month, time, day, number of injuries, accident type, cause, age, gender, pavement width, shoulder type, pavement markings and sight distance) show direct dependence relationships with severity both in the EDB and in all the clusters. This implies that those variables are highly correlated with crash severity. On the other hand, no direct link is observed between severity and atmospheric factors in the case of the EDB, whereas a relationship does exist in all the clusters identifed, highlighting the important relationship between this two variables, which has been also identify in previous studies (Mujalli and De Oña, 2011; Xie et al., 2009).

The results from inference analysis identify several variables that have an influence on KSI accidents. They are identified by $\mathrm{EDB}$, and by $\mathrm{C} 1$ and $\mathrm{C} 3$. These variables are accident type (ACT) and sight distance (SID). In all three cases (EDB, C1 and C3), when a collision with pedestrians (CP) occurs on rural highways, the probability of KSI is very high $(0.6663-0.8747$, in Table 6). Therefore, when pedestrians are frequent on such highways (i.e. on roads that link two villages that are close to each other) it is advisable to take precautions against such accidents (e.g. use of safety barriers on stretches of road where pedestrians walk on the shoulder). In the three cases it is also observed that when the SID is very restricted by topography (TOP), the probability of KSI is very high (0.6243 - 0.7497, in Table 6). Horizontal and vertical traffic signs generally take limited visibility into account (e.g. signals for overtaking other vehicles). However, the results also reveal that when SID is restricted by buildings (BUI), the probability of KSI is very high for EDB and C1. Therefore, it would be advisable to take limited visibility into account on rural highways, and to reassess visibility where there are buildings are close to the road.

Inference also shows that certain variables that have not been identified as significant with the EDB's BN in determining whether or not an accident could be KSI, are identified as significant for a specific cluster. For example, in cluster C3 if there is only one vehicle involved in a collision (i.e. fixed object collision, run-off-road collision, or collision with pedestrian) the probability of KSI is higher than the probability of SI. In cluster $\mathrm{C} 1$, the variables number of injuries, atmospheric factors, pavement markings and pavement width are found to have a significant impact on the probability of KSI. Taking into account these results, specific road safety improvements could be applied. For example, in order to reduce the severity of collisions on highways with shoulders (cluster $\mathrm{C} 1$ ), road markings should be repainted and signs of narrow lanes should be used when road markings do not exist or are deleted or when pavement 
width is less than 6 meters. None of these results would have been obtained if only the EDB had been analysed, with no prior LCC analysis.

This study shows that the combined use of both methods (LCC and BNs) provide new information and insights on the main causes of accident severity that could be useful for road safety analysts. Therefore, this study agrees with previous research (Sohn, 1999; Karlaftis and Tarko, 1998; Ng et al., 2002; Wong et al., 2004; Depaire et al., 2008; Pardillo-Mayora et al., 2010) and shows that when analysing traffic accidents, it is worthwhile to segment the accident records to increase data homogeneity before applying other analysis techniques.

Several considerations should be kept in mind when interpreting and generalizing the results of this study. The results obtained in this paper are very dependent on the initial data (two lane highways accidents with 1, 2 or 3 vehicles involved) and by the methods used (Latent Class Clustering and Bayesian Networks). Different results might have been obtained if other analysis data and methods had been used. All clustering techniques are very sensitive to the possibility of finding a local maximum instead of a global maximum. In this regard, the solution found is dependent on the initial parameter values. To prevent ending up with a local solution, the Latent GOLD program uses 10 sets of random start values (Vermunt and Magidson, 2005). Bayesian Networks need large datasets. The number of cases in EDB and $\mathrm{C} 1$ are comparable with previous studies (De Oña et al., 2011; Mujalli and De Oña, 2011). However, because of the clustering procedure, $\mathrm{C} 2, \mathrm{C} 3$ and $\mathrm{C} 4$ present a limited number of cases. Therefore, BN results for these three clusters should be interpreted carefully.

\section{ACKNOWLEDGEMENTS}

The authors are grateful to the Spanish General Directorate of Traffic (DGT) for providing the data necessary for this research. Griselda López wishes to express her acknowledgement to the regional ministry of Economy, Innovation and Science of the regional government of Andalusia (Spain) for their scholarship to train teachers and researchers in Deficit Areas, which has made this work possible. The authors also appreciate the reviewer's comments and effort in order to improve the paper.

\section{REFERENCES}

Abdelwahab, H.T., Abdel-Aty, M.A. 2001. Development of Artificial Neural Network Models to Predict Driver Injury Severity in Traffic Accidents at Signalized Intersections. Transportation Research Record, 1746, 6-13.

Abdel-Aty, M. 2003. Analysis of driver injury severity levels at multiple locations using ordered probit models. Journal of Safety Research 34, 597-603.

Acid, S., de Campos, L.M., Fernández-Luna, J.M., Rodríguez, S., Salcedo, J.L. 2004. A comparison of Learning algorithms for Bayesian networks: a case study based on data from an emergency medical service. Artificial Intelligence in Medicine, 30, 215-232.

Akaike, H. 1987. Factor analysis and AIC. Psychometrika, 52, 317-332.

Al-Ghamdi, A. 2002. Using logistic regression to estimate the influence of accident factors on accident severity. Accident Analysis and Prevention 34 (6), 729-741.

Biernacki, C., Govaert, G. 1999. Choosing models in model-based clustering and discriminant analysis. J. Statis. Comput. Simul. 64, 49-71.

Bijmolt, T.H., Paas, L.J., Vermunt, J.K. 2004. Country and Consumer Segmentation: Multilevel Latent Class Analysis of Financial Product Ownership. International Journal of Research in Marketing, 21, 323-340. 
Bock, H. 1996. Probabilistic models in cluster analysis. Computational Statistics and Data Analysis 23 (1), 5-28.

Chang, L.Y., Wang, H.W. 2006. Analysis of traffic injury severity: an application of nonparametric classification tree techniques. Accident Analysis and Prevention 38, 1019-1027.

De Oña, J., Mujalli, R.O., Calvo, F.J. 2011. Analysis of traffic accident injury on Spanish rural highways using Bayesian networks. Accident Analysis and Prevention 43, 402-411.

Depaire, B., Wets, G., Vanhoof, K. 2008. Traffic accident segmentation by means of latent class clustering. Accident Analysis and Prevention 40 (4), 1257-1266.

Dupont, E., Martensen, H., Papadimitriou, E., Yannis, G. 2010. Risk and Protection factors in fatal accidents. Accident; Analysis and Prevention, 42, 645-653.

Fraley, C., Raftery, A.E. 1998. How Many clusters? Which Clustering Method? Answers via Model-Based Cluster Analysis. The Computer Journal, 41, 578-588

Fraley, C., Raftery, A.E. 2002. Model-based clustering, Discriminant Analysis, and Density Estimation. Journal of the American Statistical Association 97 (458), 611-631.

Gray, R.C., Quddus, M.A., Evans, A. 2008. Injury severity analysis of accidents involving young male drivers in Great Britain. Journal of Safety Research 39, 483-495.

Hair, J.F.Jr., Anderson, R.E., Tatham, R.L., Black, W.C. 1998. Multivariate Data Analysis. Prentice Hall.

Helai, H., Chor, C.H., Haque, M.M. 2008. Severity of driver injury and vehicle damage in traffic crashes at intersections: a Bayesian hierarchical analysis. Accident Analysis and Prevention 40, 45-54.

Karlaftis, M., Tarko, A. 1998. Heterogeneity considerations in accident modeling. Accident Analysis and Prevention, 30(4), 425-433.

Kashani, A., Mohaymany, A. 2011. Analysis of the traffic injury severity on two-lane, two-way rural roads based on classification tree models. Safety Science 49, 1314-1320.

Kockelman, K.M., Kweon, Y.J. 2002. Driver injury severity: an application of ordered probit models. Accident Analysis and Prevention 34, 313-321.

Lord, D., Mannering, F. 2010. The statistical analysis of crash-frequency data: A review and assessment of methodological alternatives. Transportation Research Part A, 44(5), 291-305.

Ma, J., Kockelman, K. 2006. Crash Frecuency and Severity Modeling Using Clustered Data from Washintong State. IEEE Intelligent Transportation Systems Conference. Toronto, Canadá.

Magidson, J. and Vermunt, J.K. 2002. "Latent Class Models for clustering: a comparison with K-means", Canadian Journal of Marketing Research, 20, pp. 37-44.

Moustaki, I., Papageorgiou, I. 2005. Latent class models for mixed variables with applications in Archaeometry. Computational Statistics and Data Analysis 48 (3), 659-675. 
Madden, M.G. 2009. On the classification performance of TAN and general Bayesian networks. Journal of Knowledge-Based Systems 22, 489-495.

McLachlan, G.J. and Peel, D. 2000. Finite Mixture Models. Wiley, New York.

Mittal, A., Kassim, A., Tan, T. 2007. Bayesian Network Technologies: Applications and Graphical Models. IGI Publishing, New York.

Montella, A., 2011. Identifying crash contributory factors at urban roundabouts and using association rules to explore their relationships to different crash types. Accident Analysis and Prevention, 43(4), 1451-1463.

Montella, A., Aria, M., D’Ambrosio, A., Mauriello, F., 2011. Data Mining Techniques for Exploratory Analysis of Pedestrian Crashes. Transportation Research Record 2237, 107-116.

Montella, A., Aria, M., D’Ambrosio, A., Mauriello, F., in press. Analysis of powered twowheeler crashes in Italy by classification trees and rules discovery. Accident Analysis and Prevention, doi:10.1016/j.aap.2011.04.025

Mujalli, R.O. and De Oña, J. 2011. A method for simplifying the analysis of traffic accidents injury severity on two-lane highways using Bayesian networks. Journal of Safety Research, 42, $317-326$

Mujalli, R.O., De Oña, J. in press. Injury Severity Models for Motorized Vehicle Accident: A review. Proceedings of the Institution of Civil Engineers - Transport, doi:10.1680/tran.11.00026

Neapolitan, R. E. 2004. Learning Bayesian Networks. Upper Saddle River, NJ: Prentice Hall.

Ng, K.S., Hung, W.T. and Wong, W.G. 2002. An algorithm for assessing the risk of traffic accident. Journal of Safety Research 33, 387-410.

Pande, A., Abdel-Aty, M. 2009. Market basket analysis of crash data from large jurisdictions and its potential as a decision supporting tool. Safety Science 47, 145-154.

Pardillo-Mayora, J.M., Domínguez-Lira, C.A., Jurado-Piña, R. 2010. Empirical calibration of a roadside hazardousness index for Spanish two-lane rural roads. Accident Analysis and Prevention 42, 2018-2023.

Park, B.-J., Lord, D. 2009. Application of finite mixture models for vehicle crash data analysis. Accident Analysis and Prevention 41, 683-691.

Park, B.-J., Lord, D., Hart, J. 2010. Bias Properties of Bayesian Statistics in Finiture Mixture of Negative Regression Models for crash data analysis. Accident Analysis and Prevention 42, 741749 .

Raftery, A.E. 1986. A note on Bayes factors for log-linear contingency table models with vague prior information. Journal of the Royal Statistical Society, series B, 48, 249-250.

Savolainen, P., Mannering, F., Lord, D., Quddus, M. 2011. The statistical analysis of highway crash-injury severities: A review and assessment of methodological alternatives. Accident Analysis and Prevention 43, 1666-1676.

Scheier, L.M., Abdallah, A.B. Iniardi J.A., Copeland, J., Cottler, L.B. 2008. Tri-city study of Ecstasy use problems: A latent class analysis. Drug and Alcohol Dependence 98, 249-263. 
Sepúlveda, R.A. 2004. Contribuciones al Análisis de Clases latentes en Presencia de Dependencia Local. Tesis Doctoral, Universidad de Salamanca.

Simoncic, M. 2004. A Bayesian network model of two-car accidents. Journal of transportation and Statistics, 7, 13-25.

Sohn, S.Y. 1999. Quality function deployment applied to local traffic accident reduction. Accident Analysis and Prevention 31, 751-761.

Tavris, D.R., Kuhn, E.M., Layde, P.M., 2001. Age and gender patterns in motor vehicle crash injuries: importance of type of crash and occupant role. Accident Analysis and Prevention 33, $167-172$.

Vermunt, J.K., Magidson, J. 2002. Latent class cluster analysis. J.A. Hagenaars and A-L. McCutcheon (eds). Applied latent class analysis, Cambridge: Cambridge University Press. 89106.

Vermunt, J.K., Magidson, J. 2005. Latent GOLD 4.0 User's Guide. Belmont, Massachusetts: Statistical Innovations Inc."

Wong, S.C., Leung, B.S.Y., Loo, B. P.Y., Hung W.T. and Lo, H.K. 2004. A qualitative assesment methodology for road safety policy strategies. Accident Analysis and Prevention 36, 281-293.

Xie, Y., Zhang, Y., Liang, F. 2009. Crash Injury Severity Analysis Using Bayesian Ordered Probit Models. Journal of Transportation Engineering ASCE, 135(1), 18-25.

Yan X, Harb R, Radwan E. 2008 Analyses of Factors of Crash Avoidance Maneuvers Using the General Estimates System. Traffic Injury Prevention, 9, 173-180. 


\section{List of figures:}

Figure 1: Representation of BIC, AIC and CAIC in the different models.

\section{List of tables:}

Table 1 . Variables, values and actual classification by severity

Table 2. Variables, categories and probabilities of membership to each cluster

Table 3. Definition of the clusters

Table 4. Results of the Bayesian Network in the clusters and OB

Table 5. Relations between variables in the Bayesian networks

Table 6. Inference results for variables that are associated with KSI in traffic accidents for EDB, $\mathrm{C} 1$ and $\mathrm{C} 3$. 


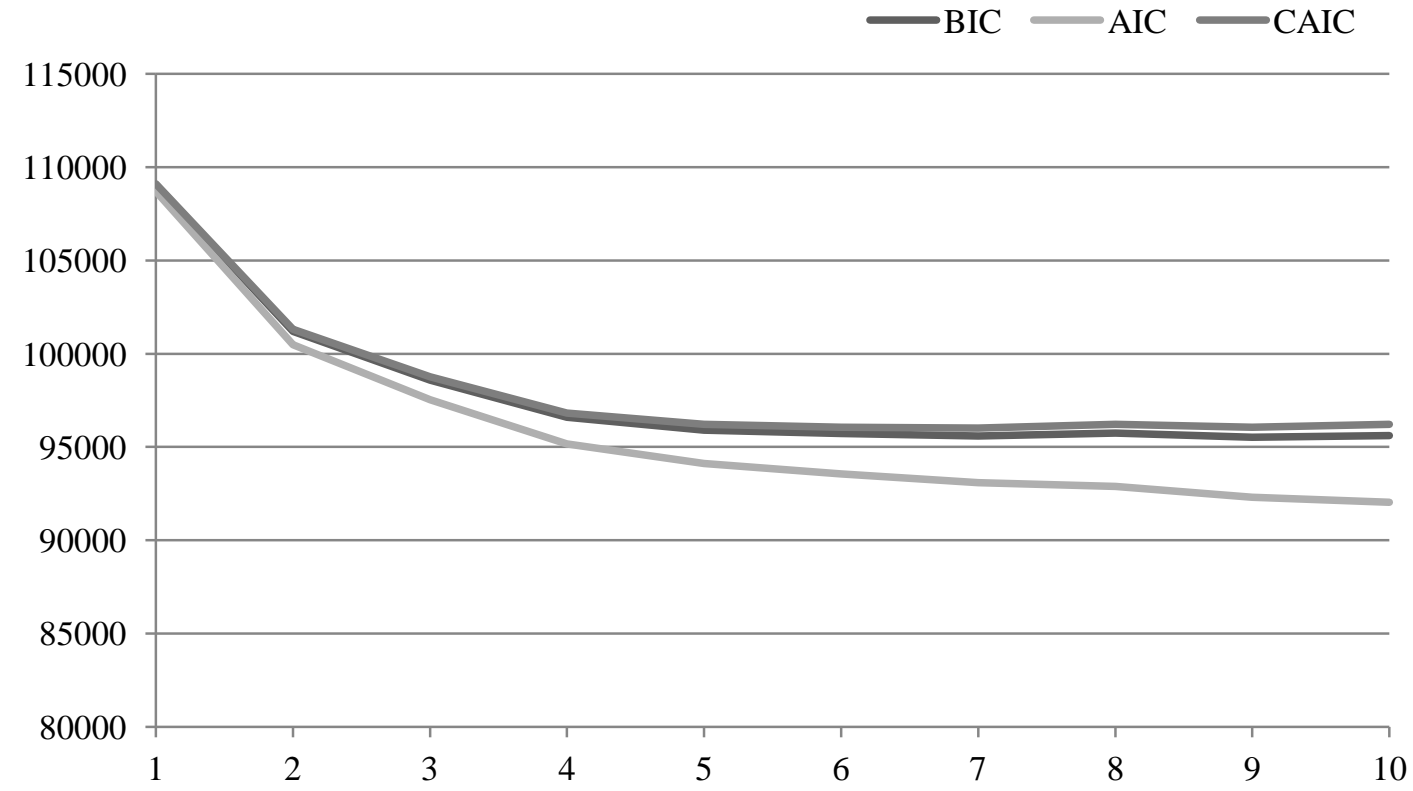

Number of estimated models

Figure 1: Representation of BIC, AIC and CAIC in the different models. 
Table 1. Variables, values and actual classification by severity

\begin{tabular}{|c|c|c|c|c|c|c|}
\hline \multirow[t]{2}{*}{ NUM } & \multirow[t]{2}{*}{ VARIABLES } & \multirow[t]{2}{*}{ CODE } & \multirow[t]{2}{*}{ VALUE } & \multirow[t]{2}{*}{ TOTAL } & \multicolumn{2}{|c|}{ SEVERITY } \\
\hline & & & & & SI & KSI \\
\hline \multirow[t]{8}{*}{1} & \multirow{8}{*}{$\begin{array}{l}\text { ACT: Accident } \\
\text { type }\end{array}$} & ASC & Angle or side collision & 1015 & $57.40 \%$ & $42.30 \%$ \\
\hline & & $\mathrm{HOC}$ & Head-on collision & 390 & $44.60 \%$ & $55.40 \%$ \\
\hline & & PUC & Pile up collision & 414 & $79.20 \%$ & $20.80 \%$ \\
\hline & & FOC & Fixed objects collision & 26 & $57.70 \%$ & $42.30 \%$ \\
\hline & & ROR & Run off road with or without collision & 1125 & $50.30 \%$ & $49.70 \%$ \\
\hline & & $\mathrm{CP}$ & Collision with pedestrian & 100 & $33.00 \%$ & $67.00 \%$ \\
\hline & & RO & Rollover & 91 & $61.50 \%$ & $38.50 \%$ \\
\hline & & OT & Other & 68 & $72.10 \%$ & $27.90 \%$ \\
\hline \multirow[t]{5}{*}{2} & \multirow[t]{5}{*}{ AGE: Age } & TEE & $<18$ or with $<18$ involved & 157 & $45.90 \%$ & $54.10 \%$ \\
\hline & & YOU & All [18-25] & 456 & $51.50 \%$ & $48.50 \%$ \\
\hline & & ADU & All (25-64] & 1782 & $56.20 \%$ & $43.80 \%$ \\
\hline & & OLD & $>64$ or with $>64$ involved & 282 & $59.90 \%$ & $40.10 \%$ \\
\hline & & YAA & [18-25] and (25-64] & 552 & $59.20 \%$ & $40.80 \%$ \\
\hline \multirow[t]{4}{*}{3} & \multirow{4}{*}{$\begin{array}{l}\text { ATF: } \\
\text { Atmospheric } \\
\text { factors }\end{array}$} & GW & Good weather & 2875 & $55.70 \%$ & $44.30 \%$ \\
\hline & & LR & Light rain & 235 & $58.70 \%$ & $41.30 \%$ \\
\hline & & HR & Heavy rain & 59 & $59.30 \%$ & $40.70 \%$ \\
\hline & & OT & Other & 60 & $48.30 \%$ & $51.70 \%$ \\
\hline \multirow[t]{4}{*}{4} & \multirow[t]{4}{*}{ CAU: Cause } & $\mathrm{DC}$ & Driver characteristics & 2969 & $55.20 \%$ & $44.80 \%$ \\
\hline & & $\mathrm{RC}$ & Road characteristics & 17 & $70.60 \%$ & $29.40 \%$ \\
\hline & & $\mathrm{VC}$ & Vehicle characteristics & 23 & $56.50 \%$ & $43.50 \%$ \\
\hline & & OT & Other & 220 & $63.60 \%$ & $36.40 \%$ \\
\hline \multirow[t]{5}{*}{5} & DAY: Day & $\mathrm{BW}$ & Beginning of week (Monday) & 417 & $60,70 \%$ & $39,30 \%$ \\
\hline & & EW & End of week (Friday) & 1198 & $55.80 \%$ & $44.20 \%$ \\
\hline & & $\mathrm{F}$ & Festive & 476 & $54.60 \%$ & $45.40 \%$ \\
\hline & & WD & $\begin{array}{l}\text { Week day (Tuesday, Wednesday, } \\
\text { Thursday) }\end{array}$ & 934 & $55.00 \%$ & $45.00 \%$ \\
\hline & & WE & Weekend (Saturday, Sunday) & 204 & $52,90 \%$ & $47,10 \%$ \\
\hline 6 & GEN: Gender & $\mathrm{M}$ & Male & 2470 & $53.60 \%$ & $46.40 \%$ \\
\hline & & $\mathrm{F}$ & Female & 252 & $58.70 \%$ & $41.30 \%$ \\
\hline & & $\mathrm{M}=\mathrm{F}$ & Male equal female & 427 & $64.90 \%$ & $35.10 \%$ \\
\hline & & $\mathrm{M}>\mathrm{F}$ & More male & 67 & $65.70 \%$ & $34.30 \%$ \\
\hline & & $\mathrm{F}>\mathrm{M}$ & More female & 13 & $76.90 \%$ & $23.10 \%$ \\
\hline 7 & LAW: Lane & THI & $<3,25 \mathrm{~m}$ & 57 & $61.40 \%$ & $38.60 \%$ \\
\hline & width & MED & {$[3,25-3,75] \mathrm{m}$} & 2494 & $57.50 \%$ & $42.50 \%$ \\
\hline & & WID & $>3,75 \mathrm{~m}$ & 678 & $49.60 \%$ & $50.40 \%$ \\
\hline 8 & LIG: Lighting & DAY & Daylight & 197 & $55.80 \%$ & $44.20 \%$ \\
\hline & & DU & Dusk & 2012 & $58.90 \%$ & $41.10 \%$ \\
\hline & & $\mathrm{IL}$ & Inssuficient & 157 & $64.30 \%$ & $35.70 \%$ \\
\hline & & SL & Sufficient & 195 & $51.30 \%$ & $48.70 \%$ \\
\hline & & WL & Without lighting & 668 & $46.00 \%$ & $54.00 \%$ \\
\hline 9 & MON: Month & WIN & Winter & 777 & $53.30 \%$ & $46.70 \%$ \\
\hline & & SPR & Spring & 791 & $57.40 \%$ & $42.60 \%$ \\
\hline & & SUM & Summer & 883 & $54.50 \%$ & $45.50 \%$ \\
\hline & & AUT & Autumn & 778 & $58.50 \%$ & $41.50 \%$ \\
\hline 10 & NOI: Number & {$[1]$} & 1 injury & 1897 & $57.00 \%$ & $43.00 \%$ \\
\hline & of injuries & [2] & 2 injuries & 785 & $54.90 \%$ & $45.10 \%$ \\
\hline & & {$[+2]$} & $>2$ injuries & 547 & $53.20 \%$ & $46.80 \%$ \\
\hline 11 & OI: Occupants & [1] & 1 occupant & 826 & $49,40 \%$ & $50.60 \%$ \\
\hline & involved & {$[2]$} & 2 occupants & 1266 & $53.20 \%$ & $46.80 \%$ \\
\hline & & {$[+2]$} & $>2$ occupants & 1137 & $63.50 \%$ & $36.50 \%$ \\
\hline 12 & PAS: Paved & $\mathrm{N}$ & No & 400 & $59.30 \%$ & $40.80 \%$ \\
\hline & shoulder & $\mathrm{Y}$ & Yes & 1960 & $56.30 \%$ & $43.70 \%$ \\
\hline & & $\mathrm{NE}$ & Does not exist or impractical & 869 & $53.30 \%$ & $46.70 \%$ \\
\hline 13 & PAW: & THI & $<6 \mathrm{~m}$ & 179 & $47.50 \%$ & $52.50 \%$ \\
\hline & Pavement & MED & {$[6-7] \mathrm{m}$} & 429 & $56.90 \%$ & $43.10 \%$ \\
\hline & width & WID & $>7 \mathrm{~m}$ & 2621 & $56.30 \%$ & $43.70 \%$ \\
\hline 14 & ROM: & DME & Does not exist or was deleted & 202 & $50.50 \%$ & $49.50 \%$ \\
\hline & Pavement & DMR & Separate margins of roadway & 98 & $54.10 \%$ & $45.90 \%$ \\
\hline & markings & SLO & Separate lanes only & 2708 & $56.80 \%$ & $43.20 \%$ \\
\hline & & SLD & Separate lanes and define road & 221 & $50.20 \%$ & $49.80 \%$ \\
\hline
\end{tabular}




\begin{tabular}{|c|c|c|c|c|c|c|}
\hline & & & margins & & & \\
\hline \multirow[t]{4}{*}{15} & \multirow{4}{*}{$\begin{array}{l}\text { SHT: Shoulder } \\
\text { type }\end{array}$} & $\mathrm{NE}$ & Does not exist or impractical & 1288 & $54.90 \%$ & $45.10 \%$ \\
\hline & & THI & $<1,5 \mathrm{~m}$ & 1527 & $55.50 \%$ & $44.50 \%$ \\
\hline & & MED & {$[1,5-2,5] \mathrm{m}$} & 407 & $59.70 \%$ & $40.30 \%$ \\
\hline & & WID & $>2,5 \mathrm{~m}$ & 7 & $85.70 \%$ & $14.30 \%$ \\
\hline \multirow[t]{6}{*}{16} & \multirow{6}{*}{$\begin{array}{l}\text { SID: Sight } \\
\text { distance }\end{array}$} & ATM & Atmosferic & 27 & $44.40 \%$ & $55.60 \%$ \\
\hline & & BUI & Building & 530 & $48.70 \%$ & $51.30 \%$ \\
\hline & & TOP & Topological & 6 & $16.70 \%$ & $83.30 \%$ \\
\hline & & VEG & Vegetation & 2 & $\begin{array}{r}100.00 \\
\%\end{array}$ & $0.00 \%$ \\
\hline & & WR & Without restriction & 13 & $38.50 \%$ & $61.50 \%$ \\
\hline & & OT & Other & 2651 & $57.60 \%$ & $42.40 \%$ \\
\hline \multirow[t]{4}{*}{17} & \multirow[t]{4}{*}{ TIM: Time } & {$[0-6]$} & {$[0-6]$} & 367 & $48.50 \%$ & $51.50 \%$ \\
\hline & & $(6-12]$ & $(6-12]$ & 842 & $59.60 \%$ & $40.40 \%$ \\
\hline & & $(12-18]$ & $(12-18]$ & 1140 & $57.50 \%$ & $42.50 \%$ \\
\hline & & $(18-24]$ & $(18-24]$ & 880 & $53.30 \%$ & $46.70 \%$ \\
\hline \multirow[t]{3}{*}{18} & \multirow{3}{*}{$\begin{array}{l}\text { VI: Vehicles } \\
\text { involved }\end{array}$} & [1] & 1 vehicle & 1285 & $49.60 \%$ & $50.40 \%$ \\
\hline & & [2] & 2 vehicles & 1738 & $59.00 \%$ & $41.00 \%$ \\
\hline & & [3] & 3 vehicles & 206 & $68.00 \%$ & $32.00 \%$ \\
\hline
\end{tabular}


Table 2: Variables, categories and probabilities of membership to each cluster

\begin{tabular}{llllll}
\hline VAR & VALUE & Cluster1 & Cluster2 & Cluster3 & Cluster4 \\
\hline \multirow{2}{*}{ OI } & 1 Occupant & $0 \%$ & $67 \%$ & $0 \%$ & $61 \%$ \\
& 2 Occupants & $48 \%$ & $22 \%$ & $53 \%$ & $25 \%$ \\
& $>$ 2 Occupants & $52 \%$ & $11 \%$ & $47 \%$ & $14 \%$ \\
\hline \multirow{2}{*}{ SHT } & Does not exist or impractical & $2 \%$ & $2 \%$ & $99 \%$ & $99 \%$ \\
& $<1,5 \mathrm{~m}$ & $77 \%$ & $78 \%$ & $1 \%$ & $1 \%$ \\
\hline \multirow{2}{*}{ PAS } & yes & $99 \%$ & $99 \%$ & $2 \%$ & $1 \%$ \\
& Without shoulder & $0 \%$ & $0 \%$ & $68 \%$ & $70 \%$ \\
\hline \multirow{2}{*}{ ACT } & Angle or side collision & $54 \%$ & $0 \%$ & $48 \%$ & $0 \%$ \\
& Head- on collision & $15 \%$ & $0 \%$ & $29 \%$ & $0 \%$ \\
& Pile up collision & $24 \%$ & $0 \%$ & $17 \%$ & $0 \%$ \\
& Fixed object collision & $1 \%$ & $1 \%$ & $1 \%$ & $1 \%$ \\
& Run-off-road with or without & & & & \\
& collision & $2 \%$ & $83 \%$ & $2 \%$ & $85 \%$ \\
\hline \multirow{2}{*}{ VI } & Collision with pedestrian & $0 \%$ & $7 \%$ & $0 \%$ & $8 \%$ \\
\hline
\end{tabular}


Table 3. Definition of the clusters.

\begin{tabular}{|c|c|c|c|}
\hline CLUSTER & CARACTERIZATION & CASES & $\%$ \\
\hline $\mathrm{C1}$ & Collisions on highways with shoulder & 1289 & $39.74 \%$ \\
\hline $\mathrm{C2}$ & $\begin{array}{l}\text { Run-off-road accidents and collisions with pedestrian } \\
\text { on highways with shoulder. }\end{array}$ & 681 & $21.06 \%$ \\
\hline C3 & Collisions on highways without shoulders & 650 & $20.24 \%$ \\
\hline C4 & $\begin{array}{l}\text { Run-off-road accidents and collisions with pedestrian } \\
\text { on highways without shoulders }\end{array}$ & 609 & $18.96 \%$ \\
\hline
\end{tabular}


Table 4. Results of the Bayesian Network in the clusters and OB.

\begin{tabular}{llllll}
\hline Subset & Accuracy & Sensitivity & Specificity & ROC Area & HMSS \\
\hline C1 & $64.0^{*}$ & $78.0^{*}$ & $56.0^{*}$ & $67.0^{*}$ & $65.0^{*}$ \\
C2 & 58.0 & 61.0 & 45.0 & 61.0 & 51.0 \\
C3 & 58.9 & $78.0^{*}$ & $71.0^{*}$ & 57.0 & $74.0^{*}$ \\
C4 & 55.1 & 47.0 & 37.0 & 56.0 & 41.0 \\
\hline EB & 59.5 & 69.0 & 52.0 & 63.0 & 59.0 \\
\hline$*$ denotes differences statistically significant $(p<0.05)$ & &
\end{tabular}


Table 5. Relations between variables in the Bayesian networks.

\begin{tabular}{|c|c|c|c|c|c|}
\hline \multirow{2}{*}{ GROUPS } & 5 groups & 4 groups & 3 groups & 2 groups & 1 group \\
\hline & $\mathrm{EDB} ; \mathrm{C} 1 ; \mathrm{C} 2 ; \mathrm{C} 3 ; \mathrm{C} 4$ & $\mathrm{C} 1 ; \mathrm{C} 2 ; \mathrm{C} 3 ; \mathrm{C} 4$ & $\mathrm{EDB} ; \mathrm{C} 1 ; \mathrm{C} 3$ & $\mathrm{EDB} ; \mathrm{C} 3$ & EDB \\
\hline \multirow{15}{*}{ RELATIONS } & TIM->LIG & \multirow[t]{15}{*}{ SEV->ATF } & GEN->VI & \multirow[t]{15}{*}{ SEV->OI } & MON->ATF \\
\hline & NOI->OI & & OI->VI & & TIM->DAY \\
\hline & PAW->LAW & & $\mathrm{EDB} ; \mathrm{C} 3 ; \mathrm{C} 4$ & & TIM->VI \\
\hline & SEV->MON & & PAW->PAS & & NOI->VI \\
\hline & SEV->TIM & & ROM->LAW & & ROM->PAS \\
\hline & SEV->DAY & & $\mathrm{C} 1 ; \mathrm{C} 2 ; \mathrm{C} 4$ & & LAW->PAS \\
\hline & SEV->NOI & & SEV->PAS & & SHT->PAS \\
\hline & SEV->PAW & & $\mathrm{EDB} ; \mathrm{C} 2 ; \mathrm{C} 4$ & & PAS->SID \\
\hline & SEV->SHT & & SEV->LIG & & PAS->VI \\
\hline & SEV->SID & & $\mathrm{EDB} ; \mathrm{C} 1 ; \mathrm{C} 4$ & & ACT $->C A U$ \\
\hline & SEV->ACT & & \multirow[t]{5}{*}{ ACT->VI } & & AGE->VI \\
\hline & SEV->CAU & & & & $\mathrm{C} 2$ \\
\hline & SEV->AGE & & & & SEV->VI \\
\hline & SEV->GEN & & & & $\mathrm{C} 1$ \\
\hline & SEV->ROM & & & & DAY->OI \\
\hline TOTAL & 15 & 1 & 7 & 1 & 13 \\
\hline
\end{tabular}


Table 6. Inference results for variables that are associated with KSI in traffic accidents for EDB, C1 and C3.

\begin{tabular}{|c|c|c|c|c|c|c|}
\hline & \multicolumn{2}{|c|}{ EDB } & \multicolumn{2}{|c|}{ C1 } & \multicolumn{2}{|c|}{ C3 } \\
\hline & SI & KSI & SI & KSI & SI & KSI \\
\hline \multicolumn{7}{|c|}{ ACT (Accident type) } \\
\hline $\mathbf{C P}$ & 0.3316 & $\underline{0.6683}$ & 0.1252 & $\underline{0.8747}$ & 0.1623 & $\underline{0.8326}$ \\
\hline HOC & 0.4462 & 0.5537 & 0.3629 & $\underline{0.6370}$ & 0.5354 & 0.4645 \\
\hline \multicolumn{7}{|c|}{ SID (Sight distance) } \\
\hline BUI & 0.4825 & 0.5174 & 0.4249 & $\underline{0.5750}$ & 0.5886 & 0.4113 \\
\hline ATM & 0.4421 & 0.5578 & 0.2144 & $\underline{0.7855}$ & 0.6256 & 0.3743 \\
\hline WR & 0.4079 & $\underline{0.5920}$ & 0.5003 & $\overline{0.4996}$ & 0.6005 & 0.3994 \\
\hline TOP & 0.2781 & 0.7218 & 0.2502 & 0.7497 & 0.3756 & 0.6243 \\
\hline \multicolumn{7}{|c|}{ TIM (Time) } \\
\hline $0-6$ & 0.4881 & $\underline{0.5118}$ & 0.5871 & 0.4128 & 0.4222 & 0.5772 \\
\hline \multicolumn{7}{|c|}{ OI (Occupants involved) } \\
\hline $\mathbf{1}$ & 0.4991 & 0.5008 & - & - & 0.2502 & 0.7497 \\
\hline \multicolumn{7}{|c|}{ AGE (Age) } \\
\hline TEE & 0.4577 & 0.5422 & 0.5489 & 0.4510 & 0.4575 & $\underline{0.5424}$ \\
\hline \multicolumn{7}{|c|}{ LIG (Lighting) } \\
\hline WL & 0.4608 & $\underline{0.5391}$ & 0.5949 & 0.4050 & 0.6090 & 0.3909 \\
\hline \multicolumn{7}{|c|}{ VI (Vehicles involved) } \\
\hline 1 & 0.5016 & 0.4983 & 0.5069 & 0.4930 & 0.4773 & $\underline{0.5226}$ \\
\hline \multicolumn{7}{|c|}{ NOI (Number of injuries) } \\
\hline$>2$ & 0.5301 & 0.4698 & 0.4881 & $\underline{\underline{0.5118}}$ & 0.6424 & 0.3575 \\
\hline \multicolumn{7}{|c|}{ ATF (Atmospheric factors) } \\
\hline OT & 0.5585 & 0.4414 & 0.3960 & $\underline{0.6039}$ & 0.9168 & 0.0831 \\
\hline \multicolumn{7}{|c|}{ ROM (Pavement markings) } \\
\hline DME & 0.5217 & 0.4782 & 0.3001 & $\underline{0.6998}$ & 0.5573 & 0.4426 \\
\hline \multicolumn{7}{|c|}{ PAW (Pavement width) } \\
\hline THI & 0.5240 & 0.4759 & 0.4932 & $\underline{0.5067}$ & 0.5942 & 0.4057 \\
\hline
\end{tabular}

